\title{
THE LOGIC OF THE FORMATION OF ACCOUNTING POLICY FOR ACCOUNTING AND COST ANALYSIS
}

\section{ЛОГИКА ФОРМИРОВАНИЯ УЧЕТНОЙ ПОЛИТИКИ ДЛЯ ЦЕЛЕЙ БУХГАЛТЕРСКОГО УЧЕТА И АНАЛИЗА РАСХОДОВ}

\author{
O. Fedotenkova, Assistant \\ О.А. Федотенкова, ассистент
}

Orel State Agrarian University, Orel City, Russia

Орловский государственный аграрный университет, г. Орёл, Россия

Phone: +7 (4862) 76-12-09, E-mail: o-fedotenkova@yandex.ru

Received December 8, 2011

\begin{abstract}
АННОТАЦИЯ
В статье уделено внимание рассмотрению факторов, влияющих на формирование учетной политики организаций элеваторного комплекса. Предложена модель формирования учетной политики для иелей управления расходами в данных организациях. Кроме того, рассмотрено коммуникативно-конгруэнтное взаимодействие бухгалтерского финансового и управленческого учета расходов.
\end{abstract}

\section{ABSTRACT \\ The article devoted to the consideration of the factors influencing the formation of accounting policy organizations elevator complex. The model of formation of a registration policy for cost management in the given organizations is offered. In addition, considered congruent commu- nicative interaction of financial and management accounting cost accounting.}

КЛЮЧЕВЫЕ СЛОВА

Учетная политика; Затраты; Расходы; Бухгалтерский учет; Финансовый учет; Управленческий учет; Организации элеваторного комплекса; Орловская область.

\section{KEY WORDS}

Accounting policies; Costs; Expenses; Accounting; Financial accounting; Managerial accounting; Organization elevator complex; Orel region.

Учетное обеспечение процесса управления расходами опирается на комплекс законодательно-нормативных актов. Локальным инструментом экономической и финансовой политики в области управления расходами является учетная политика.

Сущность учетной политики любой организации заключается в выборе одного из предлагаемых нормативными документами вариантов учета конкретных хозяйственных операций, а также самостоятельная разработка способов ведения учета и обоснование отступлений от предписаний нормативных документов.
В публикациях рассматриваются различные элементы учетной политики, как правило, с точки зрения минимизации налоговых платежей или влияния того или иного варианта, способа учета, на финансовый результат. Такие авторы как К.Н. Середа, М.А. Столярова, А.А. Адаменко отмечают, что экономически грамотно составленная учетная политика открывает возможности, при сохранении коммерческой тайны механизма формирования расходов и доходов, обеспечить прозрачность и привлекательность для потенциальных инвесторов. 
Учетная политика является средством формирования величины основных показателей деятельности организации, то есть учетная политика может выступать как:

-инструмент управления расходами, финансовыми результатами, значением статей отчетности и финансовым состоянием;

-инструмент управления величиной начисленных налогов и минимизацией налогообложения;

-действенный инструмент практического разрешения противоречий нормативных актов по бухгалтерскому учету;

-инструмент унификации учетных процедур и снижения их трудоемкости.

В процессе формирования учетной политики организации ограничиваются формальным выполнением требований ПБУ 1/2008 «Учетная политика организации» (в ред. Приказ Минфина РФ от 06.10.2008 11.03. 2009 №106н), а также правилами и нормами Налогового Кодекса.

Вместе с тем, Положение по ведению бухгалтерского учета и бухгалтерской отчетности в РФ в ред. Приказа Минфина РФ от 29.07.1998 г. № 94н, в составе основных задач бухгалтерского учета выделяет: «обеспечение информацией, необходимой внутренним и внешним пользователям бухгалтерской отчетности для контроля соблюдением законодательства при осуществлении хозяйственных операций их целесообразностью, наличием и движением имущества и обязательств, использованием материальных, трудовых, и финансовых ресурсов в соответствии с утвержденными нормами, нормативами и сметами; предотвращение отрицательных результатов хозяйственной деятельности и выявление внутрихозяйственных резервов обеспечения ее финансовой устойчивостью». Решение данных задач в учетной политике может быть достигнуто с помощью инструментов бухгалтерского управленческого учета.

Анализ сложившейся практики формирования учетной политики в организациях элеваторного комплекса показывает поверхностное отношение к формированию основного нормативного документа локального уровня, регулирующего бухгалтерский учет, и свидетельствует о том, что руководство не видит полезности от использования данных бухгалтерского учета для целей управления.

Логике формирования учетной политики используемой современными отечественными организациями, присущи следующие недостатки:

- ориентация учетной политики на максимальное использование налоговых правил, следствием чего является фискальный характер отчетности недостаточный для целей управления;

- формальное выполнение требований бухгалтерских правил (стандартов) и шаблонный характер формируемой учетной политики;

- использование методов учета, предусмотренных «по умолчанию», отказ от выбора альтернативных вариантов оценки и методов учета;

- минимизация затрат на ведение бухгалтерского учета, достигаемая путем игнорирования информационных потребностей менеджмента организации.

По нашему мнению, исправление сложившейся негативной ситуации возможно на основе интеграции финансового и управленческого учета в логике формирования учетной политики в контексте целей управления и оптимизации расходов организаций.

Таким образом, учетная политика организации может рассматриваться как эффективный инструмент управления, профессиональной оценки экономических выгод, обоснования профессионального суждения бухгалтера в соответствующих хозяйственных ситуациях.

На рис. 1 представлены факторы, оказывающие влияние на выбор и обоснование учетной политики организаций элеваторного комплекса.

Таким образом, составляя учетную политику организации необходимо принять во внимание всю совокупность влияющих факторов.

Учетная политика, в рассматриваемых организациях, формируемая для целей бухгалтерского учета в области учета расходов, должна отвечать требованиям раскрытия (организационно-технического и методологического аспектов. Так, например, в ОАО «Верховский комбикормовый 
завод» организационно-технической аспект содержит перечень приемов, используемых при построении учетного процесса. Данный аспект, формирующийся для целей учета расходов, состоит из следующих позиций: рабочего плана счетов для целей финансового и управленческого учета; система внутренней отчетности.

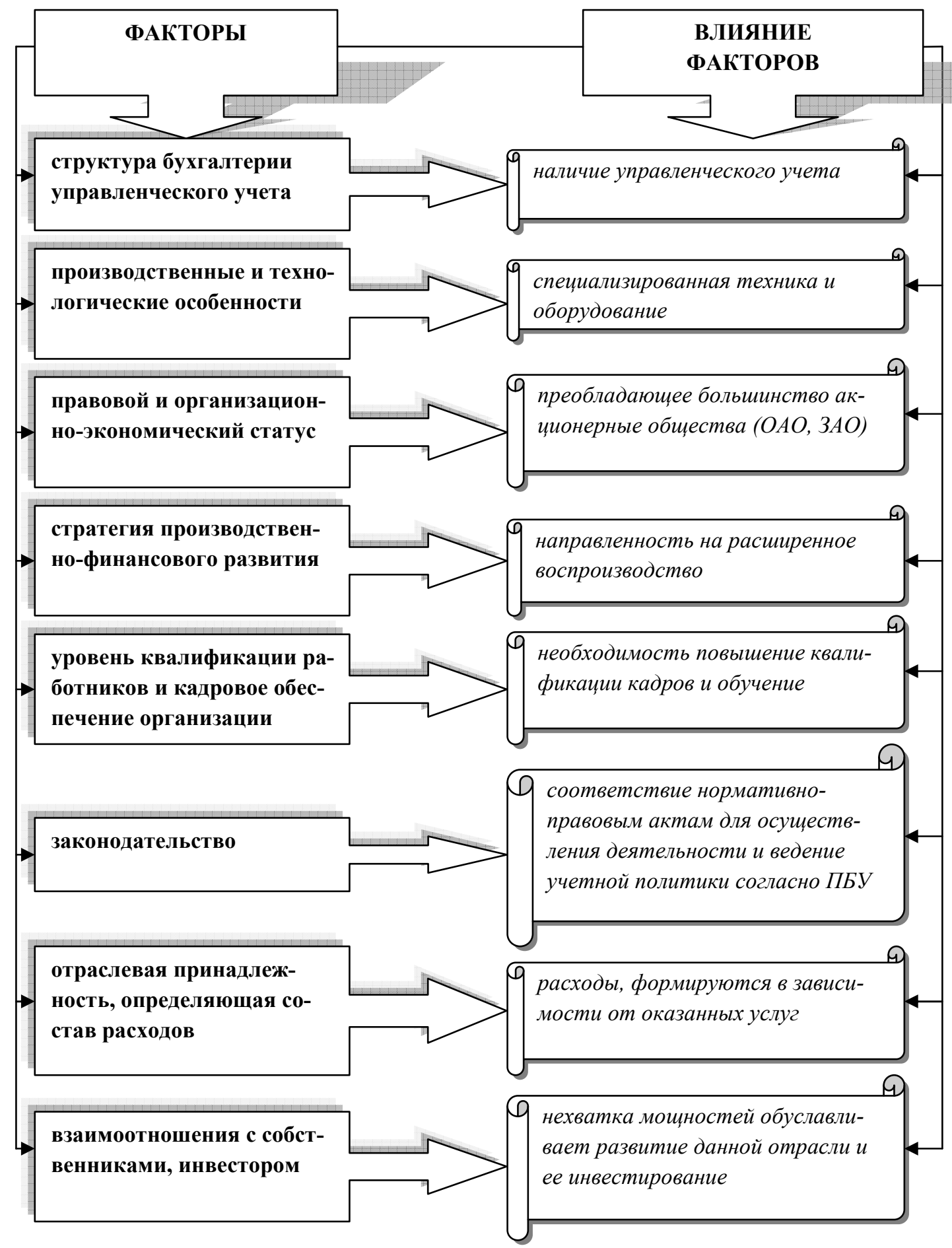

Рисунок 1 - Состав факторов, влияющих на формирование учетной политики организаций элеваторного комплекса 
К методологическим аспектам учетной политики относятся: выбор метода начисления амортизации по основным средствам и нематериальным активам; определение сроков полезного использования объектов (основных средств и нематериальных активов); отражение в учете расходов на ремонт основных средств; определение лимита стоимости имущества, подлежащего учету в составе материальнопроизводственных запасов; выбор способа оценки материалов, используемых при оказании услуг; выбор способа группировки и списания затрат; выбор состава статей калькуляции; определение перечня центров затрат; установление контролируемых расходов по каждому центру затрат; выбор варианта сводного учета затрат на производство; критерий распределения косвенных расходов между отдельными объектами учета и калькулирования; выбор методов учета затрат на производство и калькулирование себестоимости продукции; выбор способа оценки незавершенного производства; учет дебиторской и кредиторской задолженности.

В ходе исследования в организациях элеваторного комплекса г. Орла и Орловской области позволило выявить следующие проблемы организации финансового и управленческого учета:

- недостаточность детализированных и проверяемых сведений о расходах по технологическим операциям;

- высокие трудозатраты из-за параллельного учета расходов в финансовом и управленческом учете;

- проблема при переносе аналитических данных в управленческий учет;

- для разных пользователей финансовая и управленческая отчетность содержит разные цифровые данные по одним и тем же показателям;

- в каждой организации элеваторного комплекса существует бухгалтерская учетная политика, основные принципы которой предписаны официальным законодательством в соответствии с теми целями, которые ставит перед собой государство (а именно, сбор налогов). В определенных (достаточно узких) пределах организация может выбрать из предлагаемых государством вариантов учета наиболее для него целесооб- разные. Однако, для нужд управления предприятием, одной из функций которого является принятие решений на основе максимально точной оценки хозяйственного состояния организации, необходимо разработать индивидуальные основы учета;

- основной формой доведения информации о результатах деятельности производственных и других подразделений до первого руководителя являются еженедельные отчеты руководителей подразделений;

- формируемая на основе финансового учета информационная база отражает показатели в целом по организации.

Выявленные недостатки устраняются при интегрированном подходе к формированию учетной политики расходов. Нами определены основные направления в логике формирования учетной политики расходов, которые можно рассматривать как основу методических рекомендаций по превращению учетной политики организации в активный инструмент управления расходами (рис. 2).

В основу предложенных направлений развития учетной политики легли процедуры и способы формирования качественной информации для целей управления, осуществления мониторинга и аналитической диагностики расходов. Формирование учетной политики расходов организаций элеваторного комплекса нами рассматривается в целостности и единстве учетного процесса, и, прежде всего интеграционного взаимодействия финансового и управленческого учета. Принципиальная схема коммуникативного формирования учетной информации в бухгалтерской учете для целей формирования показателей финансовой и управленческой отчетности представлена на рис. 3 .

По нашему мнению, именно такой подход позволяет организациям элеваторного комплекса формировать учетную политику в области признания и отражения расходов для целей финансового и управленческого учета с учетом требования рациональности, исходя из условий хозяйствования. 


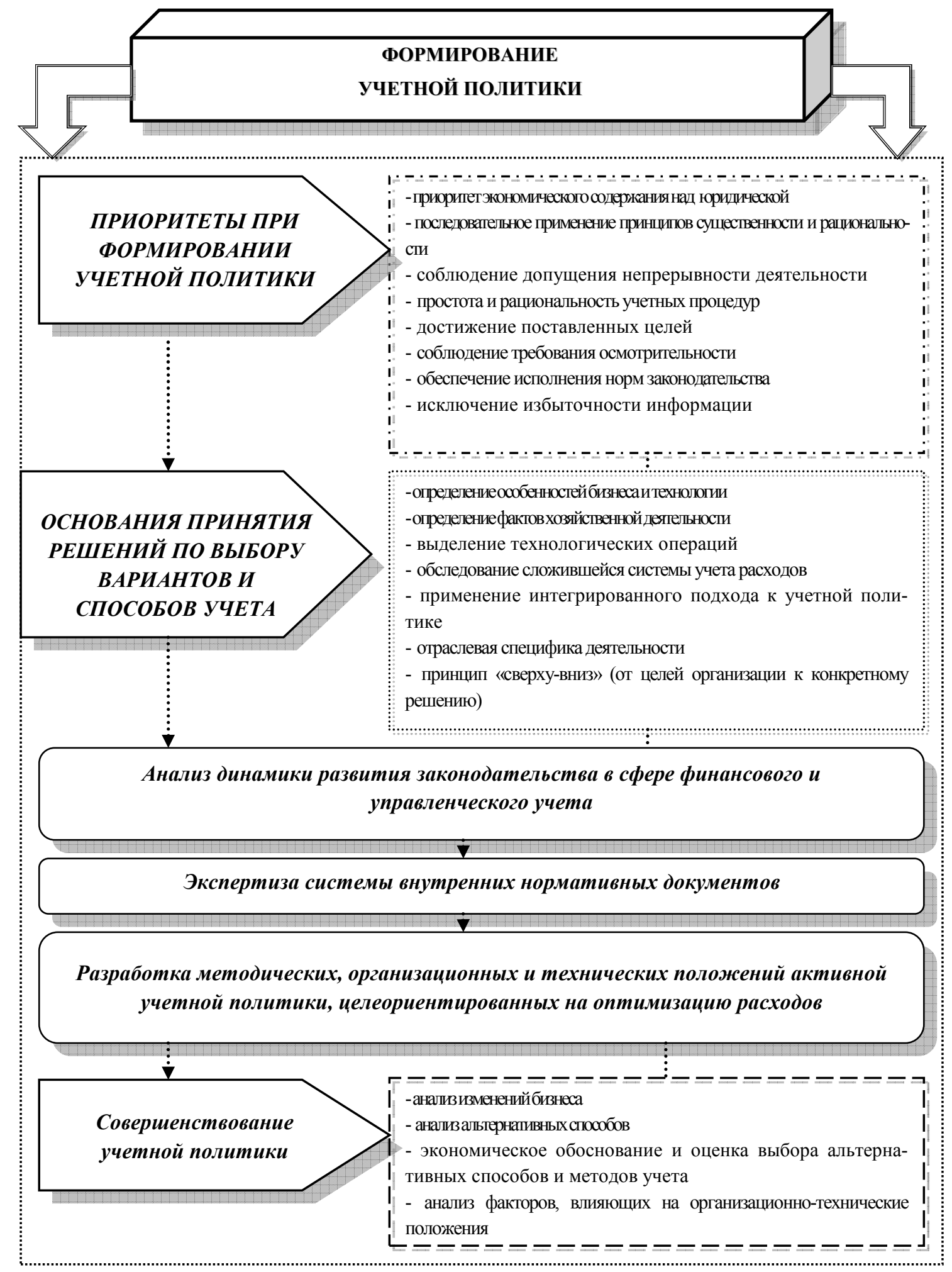

Рисунок 2 - Формирование учетной политики для целей управления расходами организаций элеваторного комплекса 


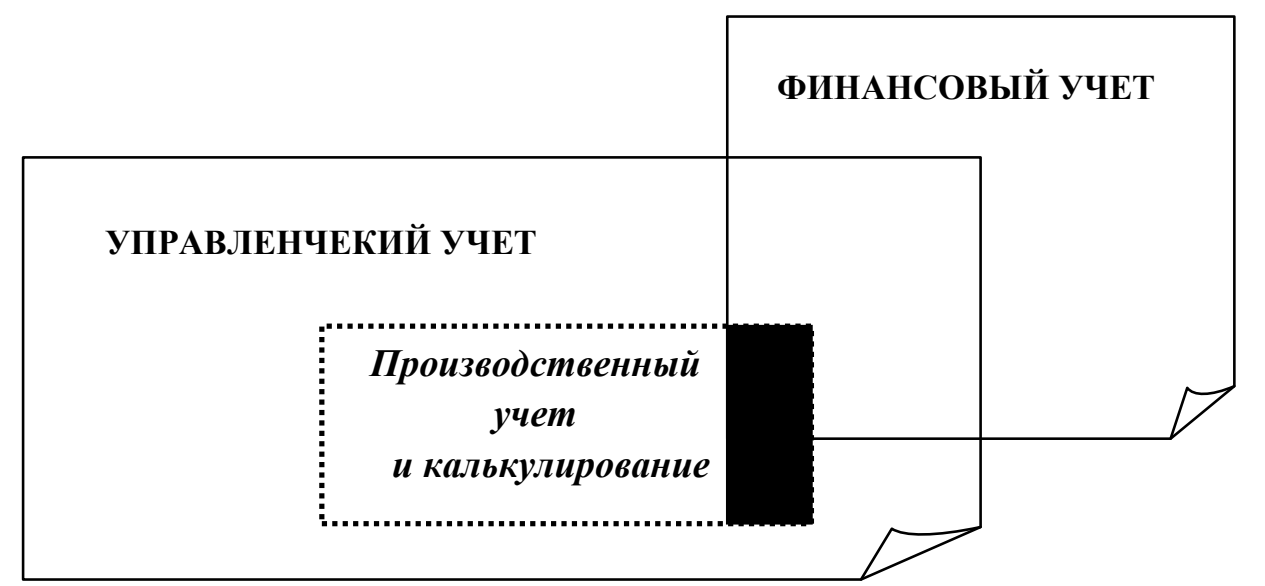

Рисунок 3 - Коммуникативно-конгруэнтное взаимодействие бухгалтерского финансового и управленческого учета расходов

Ниже приведены основные элементы учетной политики организации для целей бухгалтерского учета как инструмента управления расходами (табл. 1). Количество

элементов в учетной политике в практической деятельности может меняться в зависимости от основного вида деятельности и организационной структуры организации.

Таблица 1 - Параметры учетной политики как инструмента управления расходами для организаций элеваторного комплекса

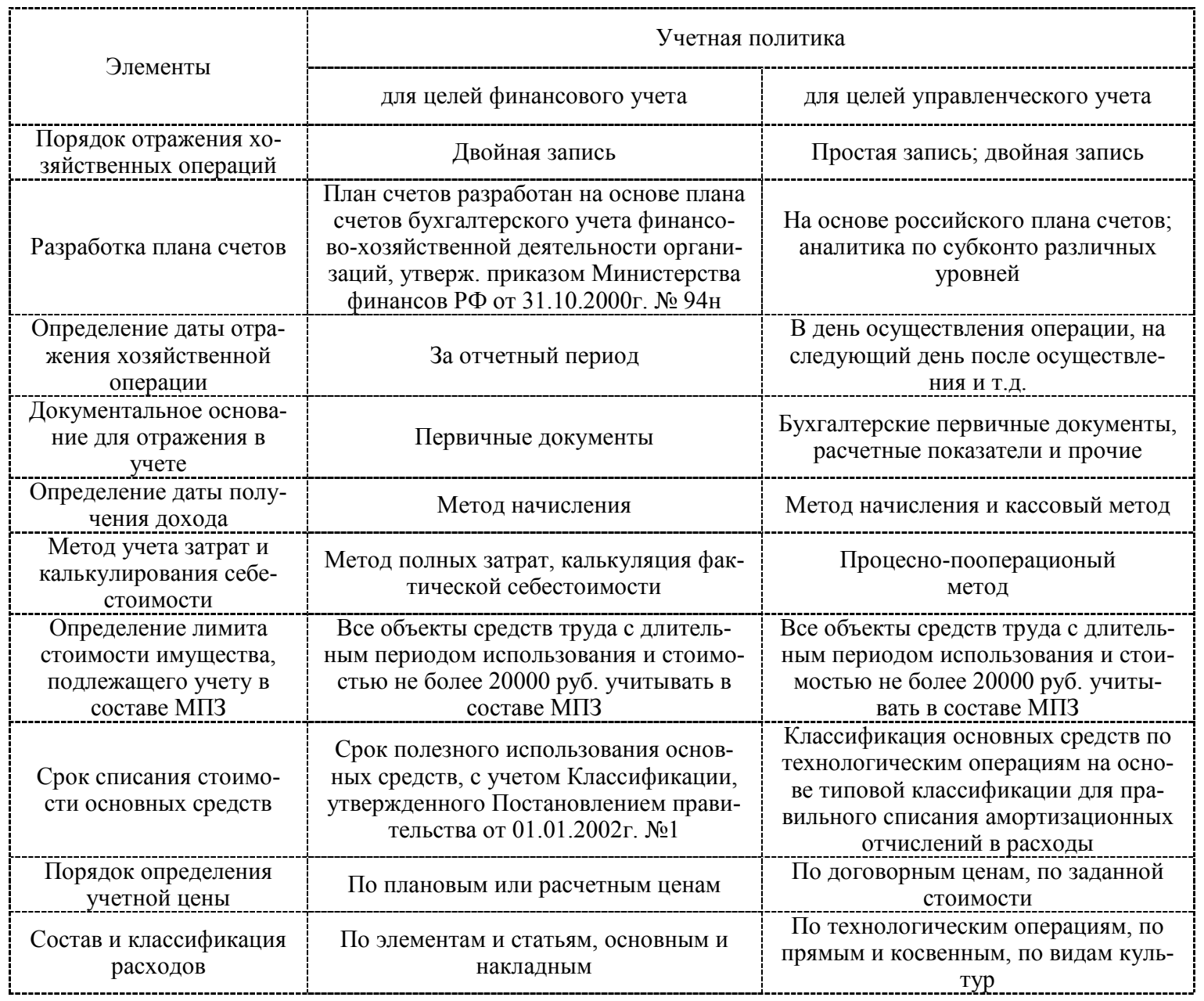


По результатам проведенного исследования нами рассмотрено формирование учетной политики в применении методов и приемов учета расходов для целей бухгалтерского учета, предложены направления ее оптимизации на основе коммуникационного взаимодействия финансового и управленческого учета и принципов рациональности, существенности и достаточности:

- состав факторов, оказывающих влияние на формирование учетной политики организаций элеваторного комплекса;

- выявлены основные проблемы формирования финансового и управленческого учета, на основе которых сформирована активная учетная политика для целей управления расходами;

- обоснованы методические аспекты учетной политики на основе интеграционного подхода финансового и управленческого учета в применении методов и приемов учетно-калькуляционных процедур;

- разработана элементная структура учетной политики расходов организаций элеваторного комплекса, обеспечивающая вариантность формирования учетной информации для целей анализа расходов по технологическим операциям.

\section{БИБЛИОГРАФИЯ}

Положение по ведению бухгалтерского учета и отчетности в Российской Федерации [Текст]: [утверждённое приказом Минфина РФ № $34 \mathrm{H}$ от 29.07.1998].

Положение по бухгалтерскому учету «Учетная политика организации» ПБУ 1/2008 [Текст]: [утверждённое приказом Минфина РФ № 106н от 06.10.2008].

Балашова Н.Н. Содержание, формирование и реализация учетной политики сельскохозяйственной организации
[Текст] /Н.Н. Балашова, М.Ф. Бычков// Бухучет в сельском хозяйстве. 2008. - № 12. - C. 9-13.

Ермакова М.С. Учетная политика в интегрированных агроформированиях [Текст]/М.С. Ермакова// Бухгалтерский учёт. - 2009. - № 6. - С. 70-71.

Игошина Ю. А. Учетная политика для сельскохозяйственных организаций в целях управленческого учета [Текст]/ Ю.А. Игошина// Вестник Алтайского государственного аграрного университета. - 2011. - № 4. - С. 115-118. 